\title{
INFLUENCE OF LIGHT ENERGY DENSITY ON HEAT GENERATION DURING PHOTOACTIVATION OF DENTAL COMPOSITES WITH DIFFERENT DENTIN AND COMPOSITE THICKNESS
}

\author{
Ricardo Danil GUIRALDO ${ }^{1}$, Simonides CONSANI ${ }^{2}$, Aline Simprine de SOUZA ${ }^{3}$, Rafael Leonardo Xediek CONSANI ${ }^{4}$, \\ Mario Alexandre Coelho SINHORETI ${ }^{2}$, Lourenço CORRER-SOBRINHO ${ }^{2}$
}

\author{
1- DDS, MSc, PhD, Professor of Post-Graduate Program at Pythagoras College, Belo Horizonte, MG, Brazil. \\ 2- DDS, MSc, PhD, Professor of Dental Materials, Department of Restorative Dentistry, Piracicaba Dental School, State University of Campinas, \\ Piracicaba, SP, Brazil. \\ 3- DDS, Graduate student, State University of Campinas, Piracicaba Dental School, Piracicaba, SP, Brazil. \\ 4- DDS, MSc, PhD, Assistant Professor of Prosthodontics, Department of Prosthodontics and Periodontics, Piracicaba Dental School, State University \\ of Campinas, Piracicaba, SP, Brazil.
}

Corresponding address: Prof. Dr. Simonides Consani - Faculdade de Odontologia de Piracicaba/UNICAMP - Av. Limeira, 901 - $13414-903$ Piracicaba, SP - Brasil - Phone: +55-19-21065347 - Fax: +55-19-21065218 - e-mail: consani@ fop.unicamp.br

Received: May 15, 2008 - Modification: November 09, 2008 - Accepted: November 16, 2008

\begin{abstract}
Q

bjective: The aim of this study was to determine the influence of different energy densities on the heat generated during photoactivation of Filtek Z250 (3M/ESPE) and Z100 (3M/ESPE) composite resins with different dentin and composite thickness. Material and Methods: The temperature increase was registered with a type-K thermocouple connected to a digital thermometer (Iopetherm 46). A chemically polymerized acrylic resin base was prepared to serve as a guide for the thermocouple and as a support for 0.5-, 1.0-, and 1.5-mm-thick bovine dentin discs. Circular elastomer molds (1.0 mm-height x 3.0-mm diameter or 2.0-mm height $\mathrm{x}$ 3.0-mm diameter) were adapted on the acrylic resin base to standardize the composite resin thickness. A conventional halogen light-curing unit (XL 2500, 3M/ESPE) was used with light intensity of $700 \mathrm{~mW} / \mathrm{cm}^{2}$. Energy density was calculated by the light intensity applied during a certain time with values of $28 \mathrm{~J} / \mathrm{cm}^{2}$ for Z100 and $14 \mathrm{~J} / \mathrm{cm}^{2}$ for Filtek Z250. The temperature change data were subjected to three-way ANOVA and Tukey's test at 5\% level. Results: The higher energy density (Z100) promoted greater temperature increase $(\mathrm{p}<0.05)$ than the lower energy density (Filtek Z250). For both composites and all composite thicknesses, the lowest dentin thickness $(0.5 \mathrm{~mm})$ yielded significantly higher $(\mathrm{p}<0.05)$ temperature increase than the other two dentin thicknesses. The 1-mm-thick composite resin layer yielded significantly higher $(\mathrm{p}<0.05)$ temperature changes for both composites and all dentin thicknesses. Conclusions: Temperature increase was influenced by higher energy density and dentin/composite thickness.
\end{abstract}

Key words: Energy density. Dentin thickness. Composite thickness. Production of heat. Temperature increase.

\section{INTRODUCTION}

A dental composite can be defined as a three-dimensional combination of at least two chemically different materials with a different interface separating the components ${ }^{14}$. Basically they are composed of an organic matrix, load particles (glass, quartz and/or melted silica) and a bonding agent, usually an organic silane, with a dual characteristic making possible the chemical bonding with the load particle and the co-polymerization with the monomers of the organic matrix ${ }^{14}$. The resin matrix is a flowing component that becomes rigid when polymerized, due to the formation of free radicals that end up inducing covalent bonds among the organic molecules, generating macro-molecules denominated polymers ${ }^{3}$. For such purpose, it is necessary that an activator-initiator system generates enough energy to break the amina molecule and form free radicals ${ }^{7,14}$.

Photoactivation is performed with visible light belonging to the blue region of the electromagnetic spectrum to excite camphorquinone, which is the most common photoinitiator present in composite resins and has an absorption spectrum in the 400 and $500 \mathrm{~nm}$ range. The most efficient wavelength range for polymerization would be between 468 and 470 $\mathrm{nm}^{13}$, which excites the camphorquinone and induces the rupture of amina ${ }^{16}$, followed by an addition reaction polymerization.

Among the light-curing units available in the market, the most traditional ones are those that use halogen lamps 
as light source. However, the main irradiation produced by those lamps is in the infrared spectral region, which is absorbed by the composite and results in great molecular vibration and generation of heat ${ }^{19}$. Thus, light sources that use halogen lamps need absorbent filters that reduce the passage of infrared energy to the tooth ${ }^{16}$. The efficiency of these filters varies according to the manufacturer and, as a result, the non-absorbed energy can produce heat.

Increase in light intensity can lead to temperature rise during polymerization due to larger radiation energy supplied by the light-curing unit ${ }^{6}$. Polymerization of composites using visible light generates a temperature increase due to both the exothermal reaction process, which is typical of addition polymerization, and the energy absorbed during irradiation with the halogen light source ${ }^{12,18}$. For this reason, when the thickness of the residual dentin is small in cavities without lining and the light intensity is high, the curing time should be minimum ${ }^{18}$.

It has been suggested that visible light photoactivation can also contribute to increase the temperature inside the pulp chamber, causing pulpal damages ${ }^{9,11,12}$. However, the findings of a recent study investigating the thermal variations in the pulp chamber associated with composite insertion techniques and light-curing methods showed that when the bulk-increment technique was used there was no significant difference in temperature increase among the photoactivation methods (Continuous, Intermittent light, or Soft-Start $)^{4}$, as well as between different shades of the same composite $^{1}$. Pulp damage can occur when a source of external heat is applied on the dental structure because the increase of the temperature inside the pulp chamber can result in an irreversible inflammatory pulpal reaction ${ }^{8,20}$.

Based on these considerations, it would be important to verify the effect of different energy densities on the heat generated during the photoactivation of Filtek Z250 and Z100 composite resins with different dentin $(0.5,1.0$, and $1.5 \mathrm{~mm}$ ) and composite $(1.0$ and $2.0 \mathrm{~mm})$ thicknesses. The null hypothesis tested was that different energy densities influence the heat produced during composite photoactivation with different dentin and composite thicknesses.

\section{MATERIAL AND METHODS}

Two restorative composite resins were used in this study: Filtek Z250 and Z100 (Figure 1). A conventional halogen light-curing unit (XL 2500, 3M/ESPE, St. Paul, MN, USA) was used with light intensity of $700 \mathrm{~mW} / \mathrm{cm}^{2}$ checked with a curing radiometer (Model 100; Demetron Research Corporation, Danbury, CT, USA). The energy density was calculated as follows: energy density $\left(\mathrm{J} / \mathrm{cm}^{2}\right)$ is the light intensity $\left(\mathrm{mW} / \mathrm{cm}^{2}\right)$ applied during a certain time (s) divided by 1,000 (Table 1 ). The spectral distributions were obtained using a spectromer (USB 2000, Ocean Optics, Dunedin, FL, USA) (Figure 2).

Temperature changes were recorded using a type-K thermocouple connected to a digital thermometer (Iopetherm 46; IOPE, São Paulo, SP, Brazil) accurate to $0.1^{\circ} \mathrm{C}$. An apparatus for temperature measurement similar to that developed by Schneider, et al. ${ }^{17}$ (2005) was used. A chemically polymerized acrylic resin base (JET; Artigos Odontológicos Clássico, São Paulo, SP, Brazil) was prepared to serve as guide for the thermocouple and as support for $0.5-, 1.0-$, and 1.5-mm-thick bovine dentin discs. The discs were positioned between the acrylic resin base and an elastomer mold to simulate different dentin thicknesses remaining after cavity preparation. Circular elastomer molds measuring either $1.0 \mathrm{~mm}$-height and $3.0-\mathrm{mm}$ diameter or 2.0-mm height and 3.0-mm diameter were adapted on the acrylic resin base to standardize the composite resin thickness (Figure 3).

The composite was inserted in the circular elastomer mold, covered with a Mylar strip and digitally pressed. For photoactivation, the tip of the light guide of the curing unit was placed in contact with the Mylar strip. The curing time was $20 \mathrm{~s}$ for Filtek Z250 and $40 \mathrm{~s}$ for Z100 according to manufacturer's instructions, which produced different energy densities. Twelve experimental groups $(n=10)$ were established from the interactions among 2 energy densities, 3 dentin thicknesses and 2 composite thicknesses (Table 1).

All measurements were taken in a temperature/humiditycontrolled room, with a constant temperature of $20^{\circ} \mathrm{C} \pm 2{ }^{\circ} \mathrm{C}$ and $30 \%$ relative humidity. For temperature measurements, the initial temperature was recorded following temperature stabilization. The composite was then light-cured and the temperature peak was registered. The initial temperature was deducted from the final temperature in order to determine the temperature increase.

\begin{tabular}{|c|c|c|c|c|c|}
\hline $\begin{array}{c}\text { Composit } \\
\text { resin }\end{array}$ & Manufacturer & Organic matrix & Filler & Shade & $\begin{array}{c}\text { Batch } \\
\text { number }\end{array}$ \\
\hline Filtek Z250 & $\begin{array}{c}\text { 3M/ESPE, St. Paul, } \\
\text { MN, USA }\end{array}$ & $\begin{array}{c}\text { BIS-GMA, UDMA and } \\
\text { BIS-EMA }\end{array}$ & $\begin{array}{c}60 \% \text { in volume }(0.19-3.3 \\
\mu \mathrm{m})-\mathrm{Zr} \text { and } \mathrm{Si}\end{array}$ & A3 & $\begin{array}{c}4 \mathrm{KG} \\
(1370 \mathrm{~A} 3)\end{array}$ \\
Z100 & $\begin{array}{c}\text { 3M/ESPE, St. Paul, } \\
\text { MN, USA }\end{array}$ & BIS-GMA, TEGDMA & $\begin{array}{c}71 \% \text { in volume (maximum } \\
4.5 \mu \mathrm{m})-\mathrm{Zr} \text { and Si }\end{array}$ & A3 & $\begin{array}{c}5 \mathrm{WE} \\
(8004 \mathrm{~A} 3)\end{array}$ \\
\hline
\end{tabular}

FIGURE 1- Tested materials 
TABLE 1 - Characteristics of the experimental groups

\begin{tabular}{|c|c|c|c|c|c|c|}
\hline $\begin{array}{l}\text { Groups } \\
(n=10)\end{array}$ & $\begin{array}{l}\text { Composite } \\
\text { resin }\end{array}$ & $\begin{array}{l}\text { Dentin } \\
\text { thickness }\end{array}$ & $\begin{array}{r}\text { Composite } \\
\text { thickness }\end{array}$ & $\begin{array}{l}\text { Light intensity } \\
\qquad\left(\mathrm{mW} / \mathrm{cm}^{2}\right)\end{array}$ & $\begin{array}{l}\text { Exposure } \\
\text { (s) }\end{array}$ & $\begin{array}{l}\text { Energy density } \\
\qquad\left(\mathrm{J} / \mathrm{cm}^{2}\right)\end{array}$ \\
\hline I & Z250 & $0.5 \mathrm{~mm}$ & $1.0 \mathrm{~mm}$ & 700 & 20 & 14 \\
\hline II & Z250 & $0.5 \mathrm{~mm}$ & $2.0 \mathrm{~mm}$ & 700 & 20 & 14 \\
\hline III & Z250 & $1.0 \mathrm{~mm}$ & $1.0 \mathrm{~mm}$ & 700 & 20 & 14 \\
\hline IV & Z250 & $1.0 \mathrm{~mm}$ & $2.0 \mathrm{~mm}$ & 700 & 20 & 14 \\
\hline V & Z250 & $1.5 \mathrm{~mm}$ & $1.0 \mathrm{~mm}$ & 700 & 20 & 14 \\
\hline VI & Z250 & $1.5 \mathrm{~mm}$ & $2.0 \mathrm{~mm}$ & 700 & 20 & 14 \\
\hline VII & Z100 & $0.5 \mathrm{~mm}$ & $1.0 \mathrm{~mm}$ & 700 & 40 & 28 \\
\hline VIII & Z100 & $0.5 \mathrm{~mm}$ & $2.0 \mathrm{~mm}$ & 700 & 40 & 28 \\
\hline IX & Z100 & $1.0 \mathrm{~mm}$ & $1.0 \mathrm{~mm}$ & 700 & 40 & 28 \\
\hline$X$ & Z100 & $1.0 \mathrm{~mm}$ & $2.0 \mathrm{~mm}$ & 700 & 40 & 28 \\
\hline$X I$ & Z100 & $1.5 \mathrm{~mm}$ & $1.0 \mathrm{~mm}$ & 700 & 40 & 28 \\
\hline XII & Z100 & $1.5 \mathrm{~mm}$ & $2.0 \mathrm{~mm}$ & 700 & 40 & 28 \\
\hline
\end{tabular}

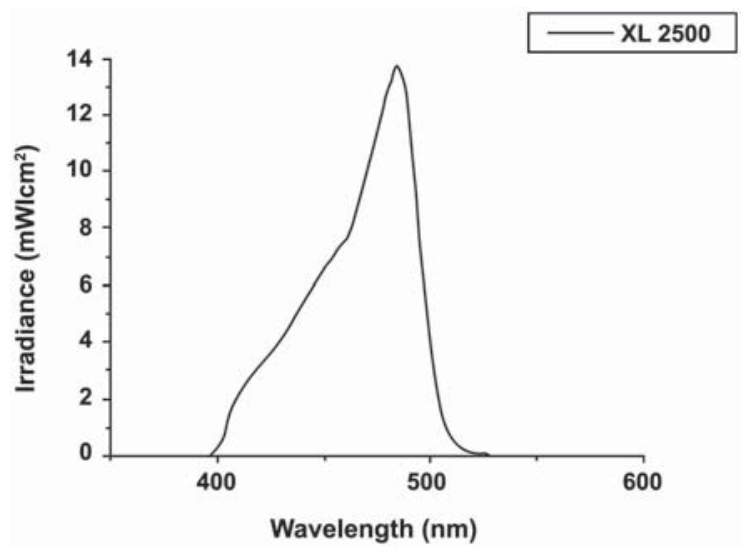

FIGURE 2- Spectral distributions of XL 2500
The temperature change data were submitted to threeway ANOVA and the means were compared by Tukey's test at $5 \%$ significance level.

\section{RESULTS}

There was statistically significant difference $(\mathrm{p}<0.05)$ for temperature increase (Table 2) between the larger energy density (Z100) and the lower energy density (Z250).

For Z250 and Z100 composites with $1.0 \mathrm{~mm}$ thickness, the $0.5 \mathrm{~mm}$-thick dentin differed significantly from the 1.0 mm-thick dentin, which in turn was significantly different $(\mathrm{p}<0.05)$ from the $1.5 \mathrm{~mm}$-thick dentin. For both composites with $2.0 \mathrm{~mm}$ in thickness, the $0.5 \mathrm{~mm}$-thick dentin differed significantly $(\mathrm{p}<0.05)$ from the other two dentin thicknesses, which however were no significantly different $(\mathrm{p}>.05)$ from

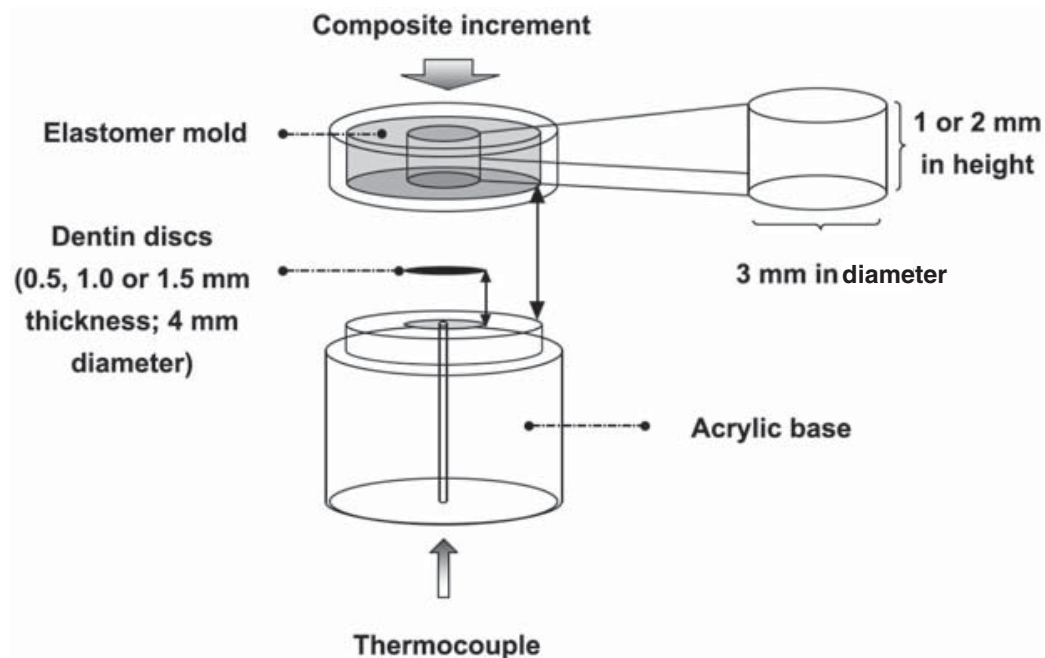

FIGURE 3- Apparatus used for measurement of temperature increase 
TABLE 2- Mean temperature increase $\left({ }^{\circ} \mathrm{C}\right)$ for $\mathrm{Z} 250$ and Z100 composite resins, regardless of the dentin and composite thicknesses

\begin{tabular}{lc}
\hline Composite & Mean temperature increase \\
\hline Z 100 & $3.18(1.12) \mathrm{a}$ \\
Filtek Z250 & $2.13(0.92) \mathrm{b}$ \\
\hline
\end{tabular}

Different letters indicate statistically significant difference (Tukey's test, $p<0.05$ ). Standard deviations are given in parentheses. restorative materials or heat generated by light-curing units $^{18,19}$. Photoactivation of composites using visible light can also contribute to the increase in temperature inside the pulp chamber, with potential thermal damages to the pulp $p^{11,12}$.

The increase of the temperature caused by photoactivation would result from the energy density emitted by the light-curing units ${ }^{5,16}$. Table 2 shows that the temperature increase produced by higher energy density (Z100) was significantly higher when compared to the lower energy density (Filtek Z250). It is likely the reason why in this study Z100 with energy density of $28 \mathrm{~J} / \mathrm{cm}^{2}$ promoted higher temperature increase than Z250 with energy density of $14 \mathrm{~J} / \mathrm{cm}^{2}$. As the same light-curing unit $\left(700 \mathrm{~mW} / \mathrm{cm}^{2}\right)$

TABLE 3- Mean temperature increase $\left({ }^{\circ} \mathrm{C}\right)$ for Z250 composite resin for each dentin and composite thickness

\begin{tabular}{lllr}
\hline Composite & Dentin thickness & \multicolumn{2}{c}{ Composite thickness } \\
& & $\mathbf{1 . 0} \mathbf{~ m m ~}$ & $\mathbf{2 . 0} \mathbf{m m}$ \\
\hline \multirow{2}{*}{ Filtek Z250 } & $0.5 \mathrm{~mm}$ & $3.87(0.38) \mathrm{a}, \mathrm{A}$ & $1.97(0.20) \mathrm{a}, \mathrm{B}$ \\
& $1.0 \mathrm{~mm}$ & $2.56(0.39) \mathrm{b}, \mathrm{A}$ & $1.34(0.17) \mathrm{b}, \mathrm{B}$ \\
& $1.5 \mathrm{~mm}$ & $1.81(0.15) \mathrm{c}, \mathrm{A}$ & $1.26(0.09) \mathrm{b}, \mathrm{B}$ \\
\hline
\end{tabular}

Different lowercase letters in columns and uppercase letters in rows indicate statistically significant difference (Tukey's test, $\mathrm{p}<0.05)$. Standard deviations are given in parentheses.

TABLE 4- Mean temperature increase $\left({ }^{\circ} \mathrm{C}\right)$ for the composite Filtek $\mathrm{Z100}$ for each dentin and composite thickness

\begin{tabular}{lllr}
\hline Composite & Dentin thickness & \multicolumn{2}{c}{ Composite thickness } \\
& & $\mathbf{1 . 0} \mathbf{~ m m ~}$ & $\mathbf{2 . 0} \mathbf{m m}$ \\
\hline \multirow{2}{*}{ Z100 } & $0.5 \mathrm{~mm}$ & $5.01(0.19) \mathrm{a}, \mathrm{A}$ & $2.95(0.30) \mathrm{a}, \mathrm{B}$ \\
& $1.0 \mathrm{~mm}$ & $4.24(0.12) \mathrm{b}, \mathrm{A}$ & $2.10(0.21) \mathrm{b}, \mathrm{B}$ \\
& $1.5 \mathrm{~mm}$ & $2.85(0.19) \mathrm{c}, \mathrm{A}$ & $1.97(0.18) \mathrm{b}, \mathrm{B}$ \\
\hline
\end{tabular}

Different lowercase letters in columns and uppercase letters in rows indicate statistically significant difference (Tukey's test, $\mathrm{p}<0.05)$. Standard deviations are given in parentheses.

each other. For both composites and all dentin thicknesses, the $1.0 \mathrm{~mm}$-thick composite layer presented significantly greater temperature changes $(\mathrm{p}<0.05)$ than the $2.0 \mathrm{~mm}$-thick composite increment (Tables 3 and 4).

\section{DISCUSSION}

The null hypothesis that different energy densities influence the heat produced during composite photoactivation with different dentin and composite thicknesses was accepted.

External heat applied to the tooth can increase the temperature in the pulp chamber resulting in irreversible damage to the pulp tissue ${ }^{8,20}$. Trauma can be induced by the cavity preparation, exothermal reaction of cements, was used for both materials, the difference in the exposure time s (40 s for Z100 and $20 \mathrm{~s}$ for Filtek Z250, as per manufacturer's instructions) seems to be the main responsible for the differences in heat generation by altering the energy density. Z100 and Z250 composites were used in this study because they possess similar organic matrixes and different filler volumes, which did not influence the increase of temperature. In this situation, the results suggest that energy density was the major factor accounting for temperature rise.

The heat that reaches the pulp can be minimized by the dentin thickness remaining after cavity preparation. The thicker the dentin layer the greater the minimization temperature that reaches the pulp because the dentin has low thermal conductivity ${ }^{10}$. This situation was observed in this study as smaller thickness of residual dentin yielded 
higher temperature increase values with statistically significant difference for both Filtek Z250 (Table 3) and Z100 (Table 4), except for the 1.0- and 1.5-mm-thick dentin discs with $2 \mathrm{~mm}$-thick composite layer. This exception suggests that the resulting heat can be lessened by using a thickest composite layer. The light passing through the polymerized composite is absorbed and reflected, thus loosing intensity ${ }^{7,15}$, which can generate similar temperature increase. Similarly, for both Filtek Z250 (Table 3) and Z100 (Table 4) composites and for all dentin thicknesses (0.5, 1.0 and $1.5 \mathrm{~mm}$ ), the $1.0-\mathrm{mm}$-thick composite layer always resulted in significantly higher temperature increase than the thickness of $2.0 \mathrm{~mm}$. A previous study showed that the heat produced in an irradiated empty cavity was always higher when compared to the polymerization of a $2.0-\mathrm{mm}$ thick composite increment. This is due to the extenuating capacity of the material to exceed the exothermal effect of the polymerization ${ }^{18}$.

Within the limitations of this study, the results seem to indicate that the temperature increase resulting from the photoactivation of composites would be well tolerable by the dental pulp, even considering the extreme condition observed with Z100 composite, in which a higher energy density $\left(28 \mathrm{~J} / \mathrm{cm}^{2}\right)$ was used with $0.5 \mathrm{~mm}$-thick dentin and $1.0 \mathrm{~mm}$-thick composite increment. It has been demonstrated that temperature changes over $5.5^{\circ} \mathrm{C}$ would be necessary to induce pulp alterations in monkey's teeth ${ }^{20}$.

\section{CONCLUSIONS}

Based on the analyzed and discussed results it may be concluded that:

1 - The higher energy density (Z100) promoted higher temperature increase than the lower energy density (Z250).

2 - For both composites and all composite thicknesses, the lowest dentin thickness yielded significantly higher temperature increase than the other two dentin thicknesses..

3 - For both composites and all dentin thicknesses, the $1.0 \mathrm{~mm}$-thick composite layer presented significantly greater temperature changes than the $2.0 \mathrm{~mm}$-thick composite increment.

4 -Temperature increase was influenced by higher energy density and dentin/composite thickness

\section{ACKNOWLEDGMENTS}

The authors wish to thank CNPq/PIBIC/UNICAMP for the financial support.

\section{REFERENCES}

1- Consani S, Farina EDP, Guiraldo RD, Sinhoreti MAC, Correr-Sobrinho L. Influence of shade and composition in the generation of heat during the dental composite photoactivation. Braz J Oral Sci. 2006;5(19):12136.
2- Goodis HE, White JM, Andrews J, Watanabe LG. Measurement of temperature gererated by visible-light-cure lamps in an in vitro mode. Dent Mater. 1989;5(4):230-4.

3- Guggenberger R, Weinmann W. Exploring beyond methacrylates. Am J Dent. 2000;13(sp. issue):82D-4D.

4- Guiraldo RD, Consani S, Sinhoreti MAC, Correr-Sobrinho L, Schneider LFJ. Thermal variations in the pulp chamber associated with composite insertion techniques and light-curing methods. J Contemp Dent Pract. 2009; 10(1):17-24.

5- Guiraldo RD, Consani S, Lympius T, Schneider LFJ, Sinhoreti MAC, Correr-Sobrinho L. Influence of the light-curing unit and thickness of residual dentin on generation of heat during composite photoactivation. J Oral Sci. 2008;50(2):137-42.

6- Hansen EK, Asmussen E. Correlation between depth of cure and temperature rise of a light-activated resin. Scand J Dent Res. 1993;101(3):176-9.

7- Knezevic A, Tarle Z, Meniga A, Sutalo J, Pichler G, Ristic M. Degree of conversion and temperature rise during polymerization of composite resin samples with blue diodes. J Oral Rehabil. 2001;28(6):586-91.

8- Lisanti VF, Zander HA. Thermal injury to normal dog teeth: in vivo measurements to pulp temperature increases and their effect on the pulp tissue. J Dent Res. 1952;31(4):548-58.

9- Lloyd CH, Joshi A, McGlynn E. Temperature rises produced by light sources and composites during curing. Dent Mater. 1986,2(4):170-4.

10- Loney RW, Price RBT. Temperature transmission of High-output lightcuring units through dentin. Oper Dent. 2001;26(5):516-20.

11- Masutani S, Setcos JC, Schinell RJ, Philips RW. Temperature rise during polymerization of visible light-activated composite resins. Dent Mater. 1998;4(4):174-8.

12- McCabe JF. Cure performance of light-activated-composites by differential thermal analysis (DTA). Dent Mater. 1985;1(6):231-4.

13- Nomoto R. Effect of light wavelength on polymerization of lightcured resins. Dent Mater J. 1997;16(1):60-73.

14- Peutzfeldt A. Resin composites in dentistry: the monomer systems. Eur J Oral Sci. 1997;105(2):97-116.

15- Rueggeberg FA, Caughman WF, Curtis JW Jr. Effect of light intensity and exposure duration on cure of resin composite. Oper Dent. 1994;19(1):26-32.

16- Rueggeberg FA. Contemporary issues in photocuring. Compend Contin Educ Dent. Suppl. 1999;(25):S4-S15.

17- Schneider LFJ, Consani S, Sinhoreti MAC, Correr-Sobrinho L, Milan FM. Temperature change and hardness with different resin composites and photo-activation methods. Oper Dent. 2005;30(4):516-21.

18- Shortall AC, Harrington E. Temperature rise during polymerization of light-activated resin composites. J Oral Rehabil. 1998;25(12):908-13.

19- Uhl A, Mills RW, Jandt KD. Polymerization and light-induced heat of dental composites cured with LED and halogen technology. Biomaterials. 2003;24(10):1809-20.

20- Zach L, Cohen G. Pulp response to externally applied heat. Oral Surg Oral Med Oral Pathol. 1965;19(4):515-30. 